\title{
Biotecnologias, transformações \\ corporais e subjetivas: saberes, \\ práticas e desigualdades
}

\section{ORG. FABÍOLA ROHDEN, CHIARA PUSSETTI E ALEJANDRA ROCA}

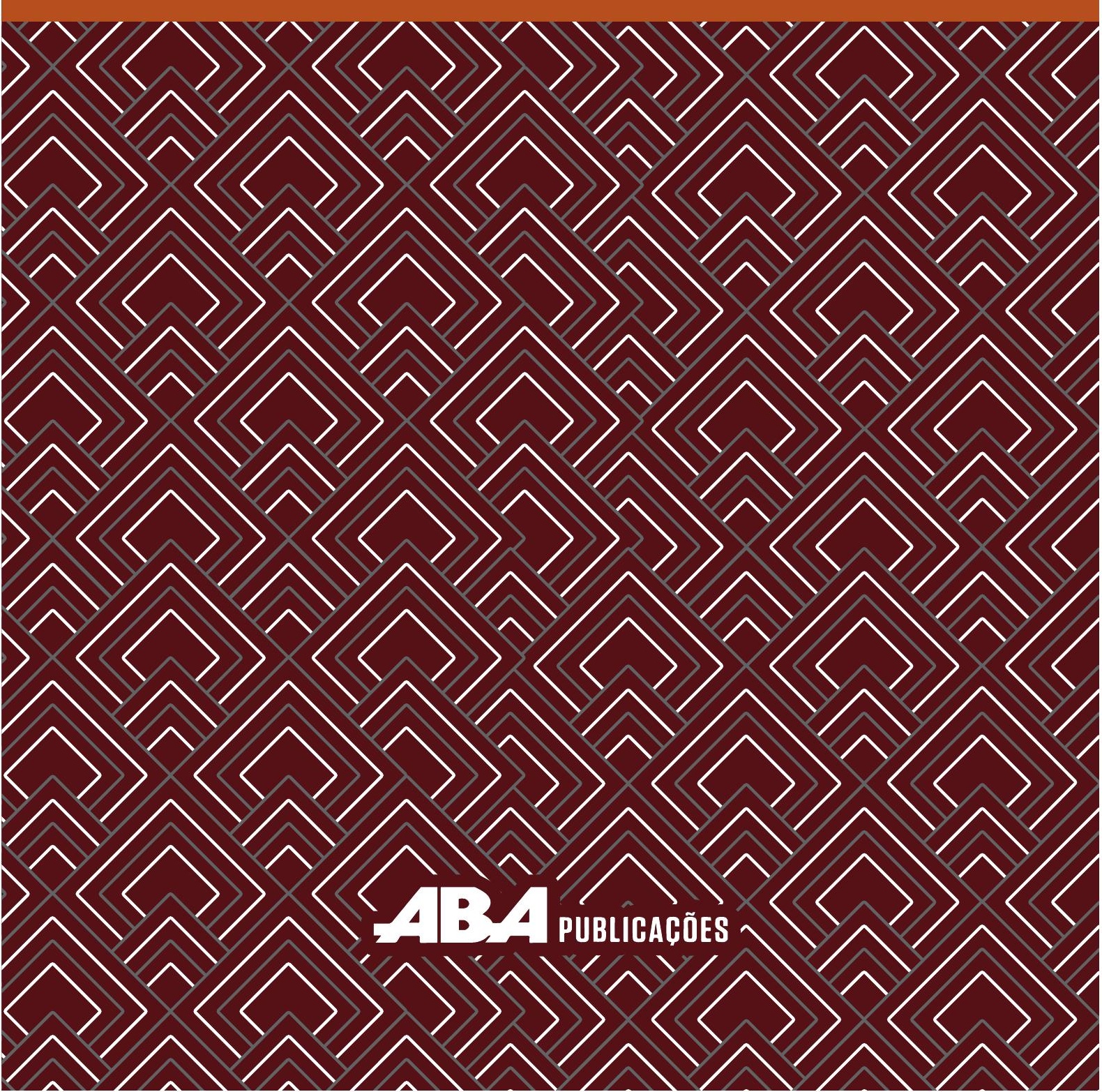


Biotecnologias, transformações corporais e subjetivas: saberes, práticas e desigualdades

\section{DOI livro - 10.48006/978-65-5973-030-8-1}

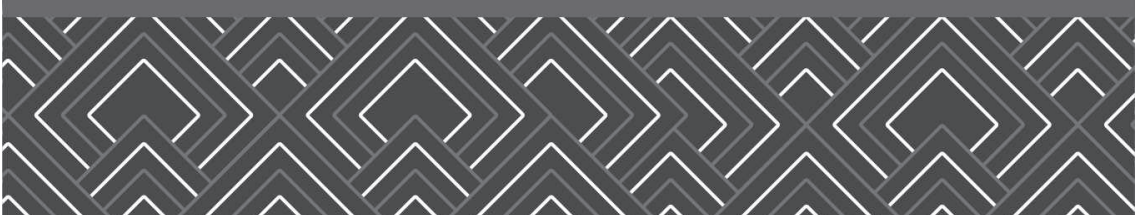

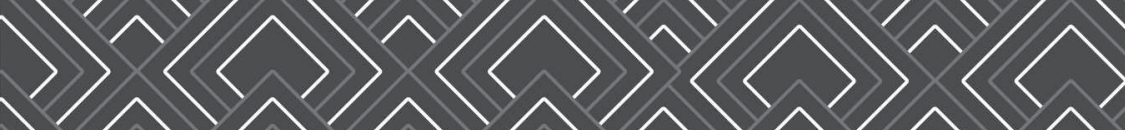
$\Delta\langle\langle\rangle\langle\langle\rangle$

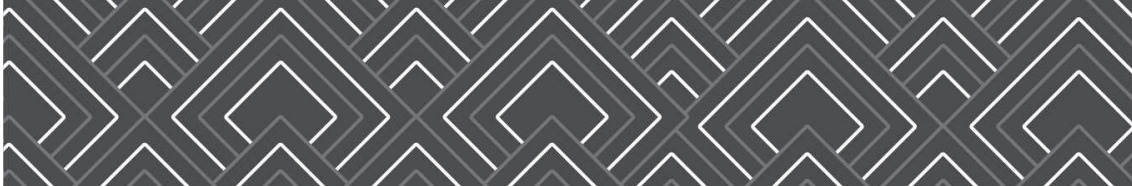

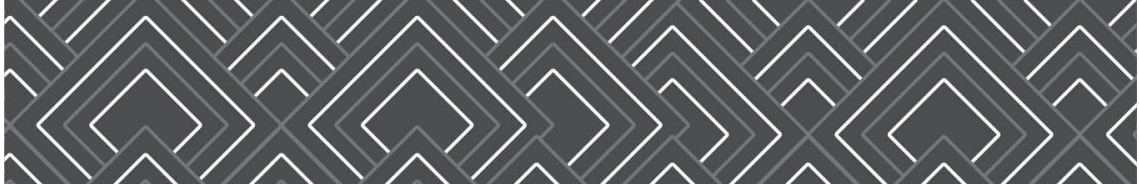
$\langle\langle\rangle\langle\langle\rangle$ $\gg\langle\langle\rangle\langle\rangle\langle<\rangle$

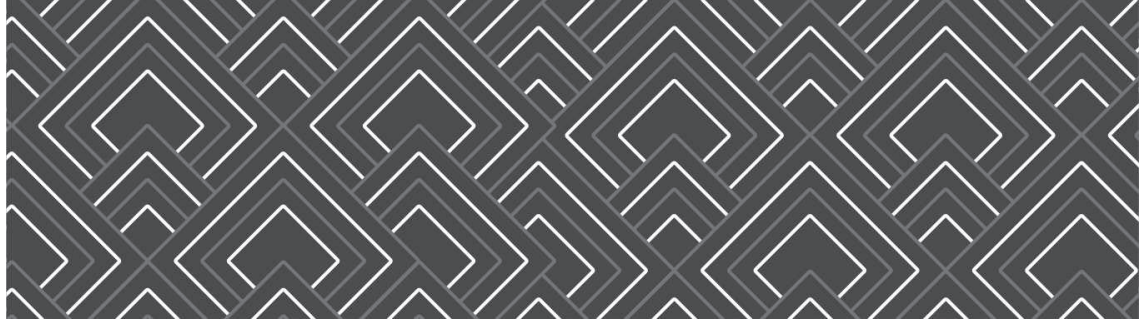




\section{COMISSÃO EDITORIAL DE LIVROS CIENTÍFICOS ABA - CELCA}

Coordenador: Carlos Alberto Steil (UFRGS)

Antônio Carlos Motta de Lima (UFPE)

Bernardo Fonseca Machado (Unicamp)

Nathanael Araújo da Silva (Unicamp)

Rodrigo Toniol (UFRJ)

Tânia Welter (UFSC)

\section{CONSELHO EDITORIAL}

Andrea Zhouri (UFMG)

Antonio Augusto

Arantes Neto (Unicamp)

Carla Costa Teixeira (UnB)

Carlos Guilherme Octaviano Valle (UFRN)

Cristiana Bastos (ICS/Universidade de Lisboa)

Cynthia Andersen Sarti (Unifesp)

Fabio Mura (UFPB)

Jorge Eremites de Oliveira (UFPel)

Maria Luiza Garnelo Pereira (Fiocruz/AM)

María Gabriela Lugones (Córdoba/Argentina)

Maristela de Paula Andrade (UFMA)

Mónica Lourdes Franch Gutiérrez (UFPB)

Patrícia Melo Sampaio (Ufam)

Ruben George Oliven (UFRGS)

Wilson Trajano Filho (UnB)

\section{ASSOCIAÇÃO BRASILEIRA DE ANTROPOLOGIA}

Presidente

Patricia Birman (UERJ)

Vice-Presidente

Cornelia Eckert (UFRGS)

Secretaria Geral

Carla Costa Teixeira (UnB)

Secretaria Adjunta

Carly Barboza Machado (UFRRJ)

Tesoureira

Andrea de Souza Lobo (UnB)

\section{Tesoureiro Adjunto}

Camilo Albuquerque de Braz (UFG)

\section{Diretor}

Fabio Mura (UFPB)

\section{Diretora}

Patrícia Maria Portela Nunes (UEMA)

\section{Diretor}

João Frederico Rickli (UFPR)

Diretora

Luciana de Oliveira Dias (UFG) 
Biotecnologias, transformações corporais e subjetivas: saberes, práticas e desigualdades

ORG. FABÍOLA ROHDEN, CHIARA PUSSETTI E ALEJANDRA ROCA

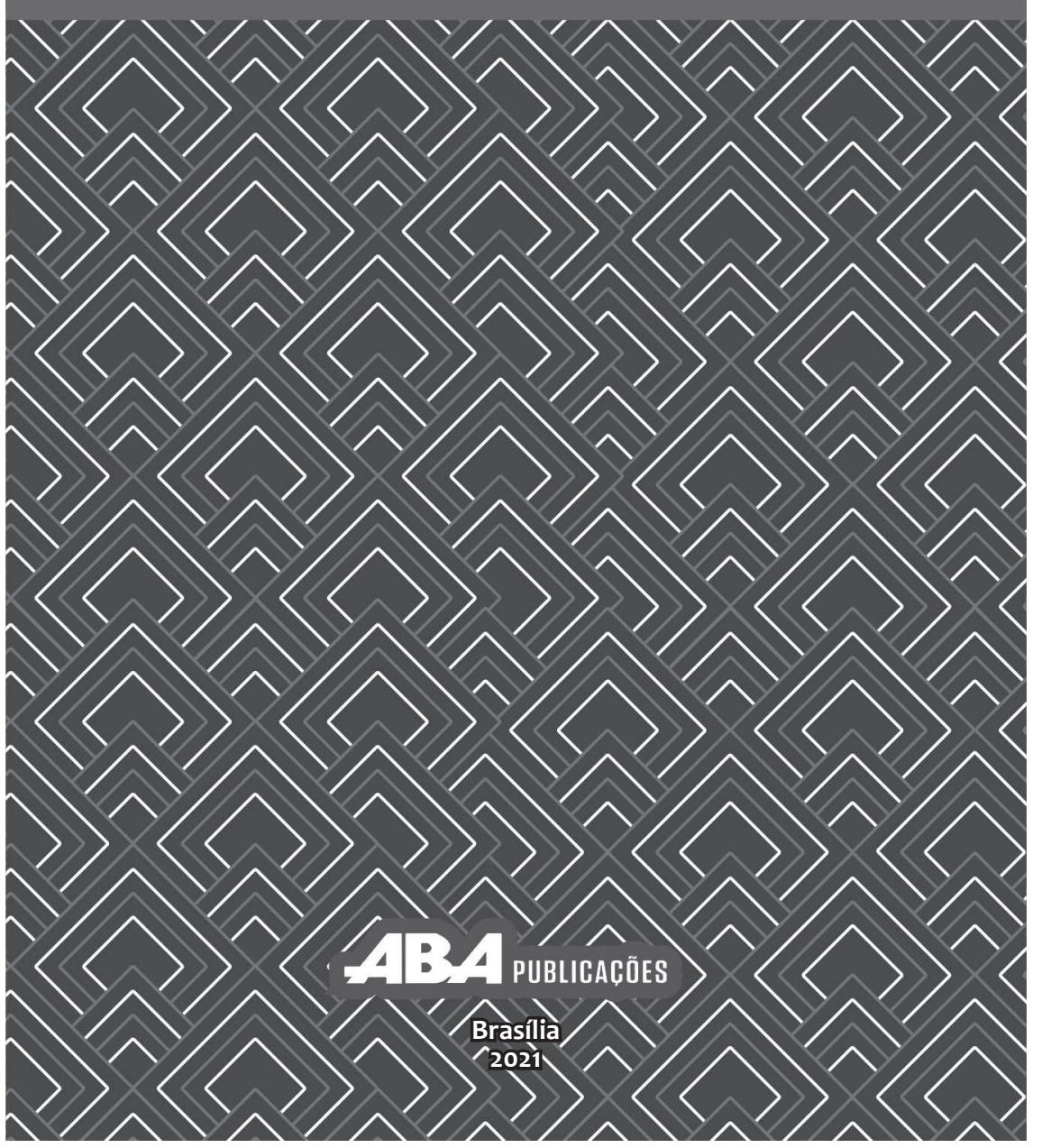


Copyright $\odot, 2021$ dos autores

\section{Organização}

Fabíola Rohden, Chiara Pussetti,

Alejandra Roca

\section{Coordenação Editorial}

Programa de Pós-Graduação

em Antropologia Social

Universidade Federal do Rio Grande do Sul

\section{Revisão}

Angélica Mello

\section{Diagramação}

Osmair Pereira

\section{Capa}

Fabíola de Carvalho Leite Peres

Coordenação editorial: Programa de Pós-Graduação em Antropologia Social da Universidade Federal do Rio Grande do Sul - PPGAS/UFRGS.

ISBN: $978-65-5973-030-8$

1. Antropologia. I. Rohden, Fabíola. II. Pussetti, Chiara. III. Roca, Alejandra.

DOI livro - 10.48006/978-65-5973-030-8-1 


\section{SUMÁRIO}

7

Introdução

Fabíola Rohden, Chiara Pussetti, Alejandra Roca

25 Dando à luz a um novo cérebro? Discursos científicos e leigos sobre mudanças cerebrais na gestação e na maternidade Jane Russo e Marina Nucci

53 Células-tronco adultas, potências condicionadas e biotecnologias de transformação

Daniela Tonelli Manica e Brunno Souza Toledo Pereira

83 'Designer babies não são futurísticos, eles já estão aqui': os testes genéticos pré-implantacionais e o futuro como prática situada de materialização Janaína Freitas

113 Quem precisa preservar a fertilidade? Gênero, tecnologia e mercado na Reprodução Assistida Débora Allebrandt

133 Olhar para dentro: Obstetrícia, tecnologias de diagnóstico e o corpo das mulheres grávidas em Portugal Maria Concetta Lo Bosco e Francesca De Luca

159 Pubertades trans: controversias en torno de los usos de tecnologías hormonales en niñxs no binarixs, en Argentina Cecilia Rustoyburu

183 Esculpindo corpos e criando normalidades: as cirurgias estéticas íntimas na produção científica da cirurgia plástica Fabíola Rohden e Camila Silveira Cavalheiro

215 'Envelhecer hoje, é uma escolha'. Responsabilidades, obrigações e promessas de juventude eterna

Chiara Pussetti e Isabel Pires 
255 Das clínicas de cirurgia plástica aos grupos online: escolher e testemunhar em novas configurações tecnológicas

Jéssica Brandt da Silva

281 Interstícios do rosto: as fissuras labiopalatinas e as intervenções cirúrgicas de reparação

Marcelle Schimitt

305 Fábulas do fim: classificações e consequências no campo da saúde Glaucia Maricato

331 De corpos universais a corpos refratários: branquitude e efeitos raciais das tecnologias biomédicas

Tatiane Pereira Muniz

357 Sobre as autoras e autor 


\section{OLHAR PARA DENTRO: OBSTETRÍCIA, TECNOLOGIAS DE DIAGNÓSTICO E O CORPO DAS MULHERES GRÁVIDAS EM PORTUGAL}

Maria Concetta Lo Bosco

Francesca De Luca

\section{Introdução}

Em outubro de 2019, um dos principais jornais portugueses ${ }^{1}$ noticiou o nascimento dramático e surpreendente de Rodrigo, um bebê nascido "sem rosto" no hospital de Setúbal, cidade do sul do Distrito de Lisboa. Segundo os relatos, apenas no momento do parto os médicos repararam que o feto não tinha desenvolvido o nariz, os olhos e parte do cérebro. $\mathrm{O}$ médico obstetra particular que acompanhou a mulher grávida não detectou qualquer malformaçáo nas três ultrassonografias de rotina que realizou ao longo da gravidez. Nos meses a seguir o nascimento do Rodrigo, que sobreviveu contra todas as probabilidades, houve muita cobertura midiática sobre o obstetra, que foi expulso da Ordem dos Médicos em Junho 2020. Outros processos foram abertos contra o médico por casos semelhantes ocorridos anteriormente, nos quais foi denunciada a falta de identificação de malformaçôes, que, em um dos casos, levou à morte do feto ainda no útero. Este episódio de negligência médica deu origem a um debate na imprensa sobre a responsabilidade dos médicos, e a ideia do poder intrínseco que é projetado nas tecnologias de diagnóstico pré-natal, o que nos permite perceber a importância crucial de refletir sobre "a vida social" das tecnologias médicas de diagnóstico - no caso específico da ultrassonografia obstétrica - e dos discursos ontológicos que as rodeiam.

Neste capítulo, iremos explorar a constituição de diferentes narrativas sobre as tecnologias de diagnóstico a partir da articulação de dois estudos etnográficos desenvolvidos em Portugal, entre 2014 e 2018. Através de entrevistas a profissionais da saúde materno-infantil e de fontes secundárias relativas à história da assistência maternal e do plane-

\footnotetext{
1 https://www.publico.pt/2019/10/17/sociedade/noticia/ha-medicos-ecografias-gravidez-devida-competencia-avisa-sociedade-portuguesa-obstetricia-1890397; https://www.publico.pt/2019/10/17/sociedade/noticia/ausencia-olhos-nariz-sao-anomalias-grosseiras-avaliadas-ecografias-1890457
} 
amento familiar em Portugal, iremos analisar como o desenvolvimento da ciência obstétrica e a implementação das técnicas de diagnóstico pré-natal são articulados com a transformação política ocorrida com o fim da ditadura e interpretados como sinais da modernidade do país. Secundariamente, analisaremos como mães de crianças diagnosticadas com autismo constroem uma nova ontologia das técnicas de diagnóstico pré-natal, a partir de uma narrativa a posteriori acerca da própria gestação: a inexistência, até hoje, de técnicas capazes de detectar o autismo durante a gravidez é re-interpretada pela mães não só como uma falha do saber diagnóstico médico, mas também como uma forma de resistência a possíveis práticas eugênicas.

Abordaremos estes assuntos através do quadro teórico de autores que têm analisado como as tecnologias de diagnóstico têm vindo a impactar o imaginário social do corpo e da maternidade. Como Van Dijck (2005) sublinha, a conjunção das tecnologias médicas visuais com as tecnologias midiáticas têm produzido ao longo dos séculos XIX-XX um conhecimento social sobre o corpo, que passa pelo ideal da "transparência". "Historicamente - sublinha o autor - esse ideal refletia noçóes de racionalidade e progresso científico; mais recentemente, a transparência passou a conotar perfectibilidade, modificabilidade e controle sobre a fisiologia humana" (Van Dijck, 2005, p. 5). Nesse cenário, o corpo grávido e o corpo do feto, mediados pelas biotecnologias de diagnóstico, tornam-se, nas práticas discursivas contemporâneas, em potenciais locus de plasticidade e intervenção (Rapp, 2000; Taylor, 2008; Morgan, 2011). Mas, se para o Van Dijck o corpo transparente promovido pela ciência médica é hoje também um produto da "cultura que capitaliza na perfectibilidade" (idem.), as experiências das mães de crianças diagnosticadas com autismo revelam uma contra narrativa que, na nossa opiniáo, pode ajudar a redefinir este ideal de transparência e perfectibilidade.

Sugerimos que as complexas relaçóes das tecnologias de diagnostico pré-natal com as experiências de maternidade podem ser compreendidas de forma melhor através das abordagens ontológicas às práticas médicas (Cussins, 1996; Mol, 2002; Thompson, 2005). Charis Cussins, ao analisar a interação entre pacientes e tecnologias médicas nas clínicas para o tratamento da infertilidade, elabora o conceito de "core- 
ografia ontológica" para indicar como "os sujeitos são dependentes da constante troca ontológica entre eles e seus ambientes” (Cussins, 1996, p. 578). Nesta perspetiva, as múltiplas narrativas e práticas produzidas socialmente, ao invés de serem interpretadas como incongruentes, refletem a dinâmica das múltiplas ontologias sobre as quais os fenômenos se articulam (Mol, 1999). Ao explorar as ramificaçóes do conceito de múltiplas realidades, Mol salienta a sua dimensão política:

se o termo 'ontologia' é combinado com o de 'política', isso sugere que as condiçôes de possibilidade não são dadas. Essa realidade não precede as práticas mundanas nas quais interagimos com ela, mas é moldada dentro dessas práticas. Portanto, o termo política serve para sublinhar esse modo ativo, esse processo de modelagem e o fato de que seu caráter é aberto e contestado (Mol, 1999, p. 75).

O contributo que este capítulo propóe é o de traçar uma possível coreografia ontológica do corpo grávido e da maternidade, revelando a complexa articulação entre biotecnologias de diagnostico pré-natal e praticas discursivas da modernidade, entre a temporalidade evocada pela Obstetrícia e marcada pelo progresso e as temporalidades críticas reclamadas pelas mães de crianças com diagnose de autismo. Enfim, entre corpos que se pretendem transparentes e plasmáveis e as imagens maçantes das multíplices experiências de maternidade.

\section{Uma genealogia da assistência materno-infantil em Portugal}

Quando se fala de saúde reprodutiva em Portugal e do desenvolvimento estrutural de políticas de assistência materno-infantil e de planeamento familiar, todos os testemunhos recolhidos através da etnografia $^{2}$, tanto de profissionais da saúde quanto de leigos, evocam o 25 de Abril de 1974 - o fim do regime ditatorial - como o ponto de viragem

\footnotetext{
2 Referimo-nos aqui à pesquisa etnográfica do projeto de doutoramento da segunda autora (2014-2020), que previu um trabalho de campo de 16 meses no Departamento de Saúde Materno-Fetal do Hospital Universitário Santa Maria, em Lisboa, mais uma extensa pesquisa de arquivo de fontes médicas e de testemunhos da história da obstetrícia em Portugal. Ao nível metodológico, o trabalho de campo incluiu observação participante na maternidade do hospital, entrevistas com mulheres gravidas, acompanhantes, com profissionais da saúde do hospital ativos ou reformados com o fim de traçar uma genealogia do parto em Portugal a partir de discursos e práticas sobre as dores de dar à luz.
} 
fundamental entre a decadência do passado e o "successo do presente". A palavra-chave transversal aos discursos médicos e às histórias de vida sobre gravidez e parto até os anos 1970 é "atraso": atraso no desenvolvimento de políticas de saúde materna, nas estruturas médicas, atraso econômico e social e atraso na mudança cultural que se tornou necessária para a aceitaçáo de novas epistemologias do corpo e da saúde da mulher que circulavam em ambientes médicos e sociais fora do país (Vicente, 1987).

Durante quarenta anos, o regime ditatorial (1933-1974) tinha promovido uma imagem da mulher dona de casa cujo papel "natural" era a maternidade e o cuidado da família e do lar (De Luca, 2018). Apesar da fundaçáo - nos anos 1930 e 1940 - dos grandes hospitais maternos nas principais cidades do país, eram relativamente poucas as mulheres que recorriam aos médicos a fim de serem assistidas durante a gravidez e o parto. Obstetras de relevo nacional, como Costa Sacadura, viam na casa o lugar normativo da reprodução, justificando que, no caso de gravidez sem patologias, a mulher-mãe não tinha razáo para se afastar da família e das suas obrigaçóes (Sacadura, 1939). Esta abordagem social à Obstetrícia promovida oficialmente pelo Estado Novo, apesar de dificultar um desenvolvimento mais estruturado e abrangente da assistência médica à maternidade, náo negava a necessidade de uma vigilância médica da gravidez para identificar fatores de riscos potenciais para a mãe e para o feto. A fim de segurar um parto sem complicaçóes, durante as gravidezes assistidas pelos médicos, eram registradas a compatibilidade da bacia da mulher com o tamanho e a posiçấo do feto. Mas, a respeito da chamada "viabilidade" do feto - termo técnico que, na Medicina Reprodutiva, indica a sua capacidade de sobreviver fora do útero - a Obstetrícia portuguesa, até o fim dos anos 1940, baseava-se nas ditas "práticas eugênicas quantitativas" típicas dos países católicos, que remetiam para uma economia da prevençáo inspirada às doutrinas da higiene social e da puericultura (Sacadura, 1938; Cleminson, 2014). Com o objetivo de conter o declínio demográfico e melhorar as condições médias de saúde, indo contra à percebida "degenerescência da raça portuguesa”, estas medidas ambicionavam a seleção pré-matrimonial, buscando desestimular a reprodução de pessoas com deformidades, 
problemas de saúde mental e doenças venéreas (Sacadura, 1938). Este cenário, caracterizado pelo conservadorismo das políticas reprodutivas, começou a mudar lentamente nos anos 1960, graças às iniciativas isoladas de profissionais da saúde que implementaram novas práticas de vigilância à gravidez de forma clandestina.

Purificação Araujo, médica obstetra, foi responsável pelo desenvolvimento de medidas de planeamento familiar e saúde das mulheres após o 25 de Abril. Nas últimas décadas do regime, foi chamada pelo Instituto Maternal, que pertencia ao Ministério dos Assuntos Sociais, para identificar os fatores de risco associados à alta mortalidade materna e infantil no país com o objetivo de implementar medidas de vigilância pré-natal. "Aquilo que se pretendia era, dentro dos dispensários, criar uma consulta de vigilância pré-natal, mas que funcionava de forma muito reduzida... Do ponto de vista cientifico e educativo, o nivel era muito baixo... tratava-se de organizar uns dossiês para melhorar a formação das enfermeiras e médicos que trabalhavam nos dispensários". Neste momento, introduziu-se, nos registros médicos de vigilância pré-natal, a identificação dos fatores de risco de doença e morte das grávidas e "criou-se um boletim para as mulheres serem estimuladas a seguir determinadas condutas de vigilância durante a gravidez". Foi observado que as principais causas de morte de foro ginecológico-obstétrico eram as hemorragias consequentes dos abortos clandestinos, os partos de mulheres muito jovens e, em contraste, os partos numerosos de mulheres com mais de 40 anos, consideradas muito "idosas". Com alguns colegas, a Doutora Araujo introduziu nas consultas o uso do teste papanicolau, uma ferramenta para o rastreio das células do colo do útero para a prevenção do câncer do útero (cujo uso se generalizou em Portugal só anos mais tarde), e realizou clandestinamente atividades de planejamento familiar a fim de permitir o espaçamento das gravidezes. Apesar de dinamizar um microcosmo de ilegalidade dentro do contexto normativo da Medicina reprodutiva do regime, "as enfermeiras - lembra a Araujo - participavam de forma espantosa. Diziam 'eu sou muito católica mas vou fazer na mesma' porque apareciam mulheres com maridos alcoólicos, com 10 filhos e com sifilis".

No final dos anos 1970, com o fim do regime ditatorial e a transição para um estado democrático, algumas práticas de planejamento 
familiar saíram da clandestinidade e tornaram-se ferramentas cruciais para reivindicar uma mudança no pensamento acerca do papel da mulher na sociedade portuguesa e para a constituição de novas políticas de saúde reprodutiva em nível nacional. As mudanças, segundo a Doutora Araujo, ocorreram a partir do dia 25 de Abril de 1974, em primeiro lugar, como reorganização espacial da Medicina reprodutiva, no sentido de reformular a topografia da saúde materno-infantil para implementar e melhorar a conexão entre os cuidados de saúde básica e os hospitais. "Havia uma ligação muito precária - continua a Araujo - no sentido da dispersão ... não tinha profissionais suficientes para cuidar disso e não havia logistica”. Dispensários ${ }^{3}$ e centros de saúde eram espalhados de forma heterogênea no território nacional, com grande concentração em Lisboa e nas suas zonas periféricas, e nas cidades do Porto e Coimbra, e com uma certa escassez no resto do país. "Então se formou uma comissão que a partir do dia 25 de Abril trabalhou nesse sentido, para implementar a conexão....". A comissão funcionou para colocar em rede os centros de saúde com os hospitais de forma mais eficaz, tratando-se de uma estratégia de extensão médica e social. "As enfermeiras tinham um carro da Direção Geral da Saúde para fazer serviços de extensão e convencer as mulheres a irem às consultas...". Outro aspecto fundamental da reforma da saúde reprodutiva após a ditadura foi a concentraçáo dos serviços materno-infantis nos hospitais centrais e o fechamento das maternidades que tivessem menos de 500 partos por ano. "Transporte e estradas melhoraram, desenvolveram-se, então colocaram as mulheres em condiçôes de irem ao hospital alguns quilômetros à frente em relação ao hospital materno". O objetivo era "garantir boas condiçöes de trabalho", através da centralização dos investimentos públicos em grandes hospitais, com a ideia de que um número mais alto de partos garantiria uma maior experiência aos médicos que ali trabalhavam. Ao nível do alcance social, o que a comissão de médicos propunha era a generalização de práticas de planejamento familiar e a maior adesão às práticas de vigilância na gravidez, no parto e no puerpério: "pediam-se análises, fazia-se a vigilância do feto sem ecografia, introduziu-se o teste de papanicolau".

\footnotetext{
3 Os dispensários eram instituições da Direção Geral da Saúde, geridas pelas Misericórdias e as freguesias que prestavam assistência médica às mães e crianças pobres através de medicamentos e consultas externas.
} 
Depois do 25 de Abril, "Portugal [entrou] em mudança acelerada" (Almeida, 2011, p. 7). Mas, como sublinha a socióloga Ana Nunes de Almeida, "a mudança não é um processo linear [...]. A mudança pode transportar do passado traços de continuidade para o presente". Um sentido de "euforia colectiva ao qual Portugal não estava habituado" marcou a passagem à década posterior (Ferreira, 2011, p. 265). No turbilhão destas transformaçôes sociais - reais, desejadas ou sonhadas a sexualidade e a maternidade ocuparam um lugar de destaque. Neste sentido, náo se pode ignorar o papel das iniciativas sociais desenvolvidas por atores sociais que trabalhavam fora da esfera médica para promover o planejamento familiar, acelerando o processo de medicalização da gravidez e do parto, através do rápido aumento do número de mulheres que recorriam aos serviços médicos para vigilância da gravidez (De Luca, 2018). Entre Outubro de 1978 e Dezembro de 1981, a Comissão para a Igualdade e Direitos das Mulheres (CIDM), instituída pela presidência do Conselho de Ministros, executou um projeto de informação, educação e comunicação sobre a saúde reprodutiva (Vicente, 1987). Através de uma colaboraçáo com a revista Crónica Feminina, entre 1979 e 1981, jornalistas especializados publicaram regularmente artigos de divulgaçáo científica sobre temas de sexualidade, contracepçáo e maternidade, convidando meninas e mulheres portuguesas a contactar a redação da revista para expressar suas dúvidas, suas experiências e perguntas acerca da própria sexualidade e maternidade. Durante o período indicado, as coordenadoras do projeto receberam mais de dez mil cartas. Estes documentos, parcialmente reproduzidos no texto de Vicente (1987), mostram como as dúvidas sobre o próprio corpo, a sexualidade e a experiência da maternidade são reflexos dos silêncios, incutidos por décadas nos níveis social e político pela ditadura. Se, por um lado, iniciativas como a da CIDM são usadas para fundamentar a aceleraçáo do país rumo à modernidade, do outro eles revelam como "a realidade contemporânea de um país onde se combinam no presente, por vezes em arranjos híbridos e paradoxais, tempos portadores de várias histórias é um dos resultados desse processo" (Almeida, 2011, p. 7). 


\section{Da arte à ciência obstétrica}

Como analisado, as narrativas sobre a história (médica) da maternidade em Portugal frequentemente traçam uma linha clara de viragem antes e depois do 25 de Abril. Tanto profissionais de saúde quanto pessoas comuns destacam a mudança que o país viveu no declínio da taxa de mortalidade materna e infantil após o fim da ditadura (Neves; Ayres-De-Campos, 2012). É uma narrativa social sintetizada, por exemplo, no documentário "Nascido para viver" $(2012)^{4}$, que reconstrói, através de imagens de arquivo e por meio de entrevistas com médicas/os e enfermeiras que trabalharam durante a transição política, as precárias condiçóes de vida da época e comemora as açōes que foram implementadas para combater as lacunas e carências do sistema de assistência materna e à primeira infância. Como já observado, ao nível narrativo, este contraste temporal entre a imobilidade do passado e a modernidade do presente é especialmente articulado para sustentar a importância da adesão às práticas médicas de vigilância da gravidez através de tecnologias de diagnóstico e do parto hospitalar. A reduçáo da taxa de mortalidade infantil é o principal argumento veiculado em contraposição às reivindicaçôes de associaçôes e movimentos civis que defendem a pluralidade de modelos de gestão da gravidez e do parto, apelando a práticas menos intervencionistas (White, 2016; Fedele; White, 2018).

Mas o que é identificado como fonte de transformação nem sempre coincide. Segundo o Prof. Graça, ex-diretor do Departamento Materno-Infantil do Hospital Universitário Santa Maria, em Lisboa e Presidente da Associação Portuguesa de Obstetrícia, as mudanças do foro da saúde reprodutiva, nos anos 1970, foram geradas principalmente pela emergência das tecnologias de diagnóstico pré-natal e pelo advento da Medicina Molecular e da Medicina baseada na evidência no panorama da Biomedicina. Essa virada significou, na sua narrativa, o desenvolvimento de uma série de exames e práticas perinatais aptas a garantir um melhor resultado do parto tanto para a mãe quanto para o bebê. É principalmente com estas tecnologias, em particular com as ultrassonografias obstétricas e, mais tarde, com os testes genéticos, que a Obstetrícia se torna, segundo o Prof. Graça, de "arte do parto" à "ciência do parto", reproduzindo um tropo

4 Documentário produzido pela Fundação Francisco Manuel Dos Santos em 2012 e disponível online: https://www. youtube.com/watch?v=A6GketN3FbU 
frequente ao longo da história da Obstetrícia como disciplina médica, como foi aprofundado por Barreto (2007).

Apesar de ter se formado como médico nos anos 1970 e de ter sido testemunha das transformaçóes das políticas reprodutivas em Portugal, o Prof. Graça afirma ser mais um "técnico" do que uma pessoa orientada para a história da Obstetrícia. No momento da entrevista (2017), o médico estava a trabalhar na quinta edição do seu manual de Obstetrícia, "Medicina Materno-Fetal", texto de referência dos cursos nacionais da disciplina cuja edição precedente remonta a 2010. À nossa pergunta se houve avanços importantes na disciplina durante o tempo, entre a última e a recente edição, ele respondeu afirmativamente, alegando que as principais mudanças aconteceram no diagnóstico pré-natal, em particular no rastreio da pré-eclâmpsia e na diabetes gestacional. O obstetra sublinhou, mais uma vez, como, a partir destas tecnologias e no aumentado da capacidade de "olhar para dentro", a Obstetrícia passou de arte à ciência. Se de um lado, como vários estudos socioantropológicos têm demonstrado, a midiatizaçáo da cultura médico-visual inaugura a entrada do feto na cena médica reprodutiva - Martin (1987) e Taylor (2008) falam do desaparecimento da mulher grávida e do aparecimento do feto como sujeito político - o discurso do Prof. Graça revela um aspecto, às vezes menos analisado, centrado na fundação de uma nova epistemologia da disciplina obstétrica. Através das tecnologias de diagnóstico e Medicina baseadas na imagem, a Obstetrícia liga-se, sobrepóe e interconecta-se com o aparato mais amplo da Biomedicina contemporânea, virada - segundo o argumento do Van Dijck (2005), à perfetibilidade do corpo humano. No formular uma ontologia da moderna Obstetrícia, que se constitui graças ao desenvolvimento da Medicina Molecular, o Prof. Graça sinaliza um argumento político que eleva a Obstetrícia ao mesmo nível de outras especialidades médicas, potencialmente adquirindo conhecimentos e técnicas baseadas na evidência científica que permitiam agora intervir não só na parturiente, mas também no feto enquanto ainda no útero. Como observa Wendland, "esta nova ênfase na evidência científica é estimulada por uma percepçáo de longa data de que a Obstetrícia é um dos ramos menos científicos da Medicina Clínica" (Wendland, 2007, p. 218). Nas palavras do prof. 
Graça "o obstétrico é praticamente um médico de medicina interna, porque ele deve ter conhecimentos de nefrologia, cardiologia, técnicas diagnósticas etc. relativamente ao corpo grávido".

Dentro do discurso da "molecularização" do conhecimento científico-médico sobre a gravidez e o parto, muda-se não só a geografia do corpo grávido, mas se estabelece também o processo de transformaçáo da geografia das instituiçóes obstétricas no sentido da polarização das Unidades Materno-Infantis nos hospitais centrais, como já observado pela Doutora Araujo. A abordagem interpretativa do Prof. Graça caracteriza-se, porém, na ênfase dada mais uma vez ao novo papel científico da Obstetrícia: "Os avanços nas tecnologias de diagnóstico pré-natal e a transformação da obstetricia tornaram obsoletas as maternidades, isso é, os hospitais especializados em saúde materna". O hospital central, com todos os departamentos organizados num espaço contíguo é o reflexo, na sua perspetiva, desta articulação das disciplinas médicas que são, no seu entendimento, entrelaçadas a todos os níveis. A nova epistemologia da Obstetrícia, como disciplina integrada às outras especialidades médicas, abrindo novos campos de intervenção, torna necessária a transformação do espaço em que a Obstetrícia operava: o hospital centralizado ganhou um novo destaque, e a política de aglomeraçáo das unidades maternas fazia com que a sobrevivência dos departamentos maternos dependesse do número de partos por ano na unidade.

A transformação da Obstetrícia de arte para ciência revela o novo lugar que a, tradicionalmente, irmã menor das especializaçóes médicas tem ganhado com a percebida e proclamada possibilidade de intervir "no interior" do corpo grávido. Através das tecnologias de diagnóstico pré-natais desenvolvidas a partir dos anos 1970 - coincidente, em Portugal, com a transição para o regime democrático - os corpos da grávida e do feto tornam-se, nesta ontologia do conhecimento médico-obstétrico, virtualmente transparentes ao olhar médico.

\section{Dentro e fora do útero}

Como já mencionamos, a difusão e o uso das tecnologias de diagnóstico pré-natal contribuiu para transformar a Obstetrícia na assim chamada "ciência do parto", graças à aquisição de conhecimentos e 
técnicas que permitem aos profissionais de saúde ver e (intervir) dentro e fora do útero da mulher. $\mathrm{O}$ que acontece, porém, quando uma condição como o autismo - pelo facto de ser até hoje indetectável dentro do útero - torna opaca e falível a qualidade intrínseca da Medicina Diagnóstica pré-natal de avaliar o estado fetal e permitir, portanto, um aconselhamento parental atempado e uma adequada programaçáo do nascimento? Quais são as ontologias mobilizadas pelas mulheres sobre a Medicina Preventiva, os saberes e as técnicas a esta relacionadas após receber o diagnóstico de autismo do próprio filho fora do útero?

Os Transtornos do Espectro Autista (TEA) ${ }^{5}$ englobam diferentes síndromes, marcadas por perturbaçôes do desenvolvimento neurológico, que afetam a comunicação verbal e a interação social. São caracterizados por padróes de comportamentos repetitivos e estereotipados e por um repertório restrito de interesses e atividades (APA, 2015). Os sintomas manifestam-se, geralmente, nos primeiros três anos de vida, e o diagnóstico, feito por um especialista em Pedopsiquiatria e/ou por uma equipe multidisciplinar, é baseado na observação clínica de um conjunto de sinais comportamentais (entre os quais, interesses fixos, açóes obsessivas e repetitivas, reaçóes intensas à estimulaçáo sensorial ou dificuldades na relação), assim como em entrevistas com os pais e pela aplicação de instrumentos específicos, de acordo com critérios descritos no DSM, o Manual Estatístico e Diagnóstico da Associação Americana de Psiquiatria 6 . Os dados epidemiológicos estimam que, no mundo, uma a cada oitenta e oito crianças apresenta sintomas relacionados com o TEA, sendo que, em 2010, no Brasil, estimava-se cerca de 500 mil pessoas com autismo (Gomes et al., 2015, p. 111). Em Portugal, enquanto o único e último estudo epidemiológico, publicado em 2005 com dados recolhidos no ano 2000, revelava uma prevalência global de 9,2 por 10000 casos no Continente e de 15,6 por 10000 casos nos Açores (Oliveira et al., 2007, p. 729), recentemente os números apontam para $0,5 \%$, num total de cerca de 50

\footnotetext{
5 Em Psiquiatria e em Psicologia, utilizam-se os termos de transtornos, perturbações ou distúrbios para descrever quadros clínicos onde há um comprometimento ou uma alteração do quadro psicológico do indivíduo. Ao longo do tempo, e de acordo com os diferentes contextos nacionais, foram utilizadas diferentes nomenclaturas para o autismo. Neste texto, iremos utilizar a nomenclatura TEA. No entanto, em Portugal é geralmente preferível o uso do termo PEA, Perturbações do Espectro do Autismo.

6 Para uma revisão dos instrumentos clínicos com vistas ao rastreamento dos sinais precoces do autismo, ver Seize e Borsa (2017).
} 
mil pessoas ${ }^{7}$. Embora estudos recentes na área da Medicina Genética e da Neurofisiologia têm avançado diferentes hipóteses na tentativa de descobrir a origem do autismo, (Robinson et al., 2015) para uma revisão da literatura, a sua etiologia continua ainda desconhecida. É geralmente aceita a hipótese de uma origem multifatorial, ou seja, de numa combinação de alterações genéticas, ambientais e neurobiológicas, mas não existem, de fato, biomarcadores, isto é, características biológicas que permitem identificar se uma criança tem autismo ou medir as alteraçóes do seu circuito cerebral. Apesar de pesquisas recentes (Auyeung et al., 2009; Stoner et al., 2014 $)^{8}$ sugerirem que mudanças ocorridas durante a concepção, gravidez e, possivelmente, até o parto podem aumentar o risco de autismo em crianças que são geneticamente predispostas ao distúrbio, até hoje, as técnicas de diagnóstico pré-natal ,como a ultrassonografia obstétrica, a amniocentese (a recolha e análise de líquido amniótico que permite determinar anomalias cromossômicas que o feto possa ter) ou até testes genéticos, não "conseguem" detectar o risco de autismo dentro do útero.

Os dados etnográficos e as reflexóes que aqui são apresentadas baseiam-se num trabalho de campo desenvolvido em Portugal e que teve como objetivo principal estudar as reivindicaçóes e as lutas de pais de crianças diagnosticadas com TEA (Lo Bosco, 2018) ${ }^{9}$. Em muitas das entrevistas recolhidas assim como das conversas informais, as mães sublinham como a adaptação à nova realidade de ter um filho com

$7 \mathrm{https} / /$ expresso.pt/sociedade/2020-08-01-50-mil-portugueses-tem-perturbacoes-do-espectro-do-autismo

8 O estudo exploratório no New England Journal of Medicine (Stoner et al., 2014) mostra um excesso de neurônios no córtex pré-frontal em crianças com autismo já no segundo trimestre de gravidez, sinalizando, portanto, uma provável disfunção da diferenciação neuronal em estágios de desenvolvimento pré-natal. Através da técnica de hibridização de RNA, os investigadores individuaram marcadores neuronais e genéticos hipoteticamente implicados no risco de autismo no tecido neocortical de amostras post-mortem, obtidas de crianças diagnosticadas com autismo e crianças não afetadas, com idades entre 2 e 15 anos. O estudo do Cambridge University Autism Research Center sobre 235 crianças observadas desde o nascimento até os 8 anos de idade mostrou que níveis elevados de testosterona no líquido amniótico da mãe estão associados a futuros traços autistas na criança (Auyeung et al., 2009)

9 Referimo-nos aqui ao projeto de doutoramento (2013-2018) da primeira autora, que previu um trabalho de campo de 14 meses na área metropolitana de Lisboa. Foi utilizado o método da observação participante e de entrevistas não estruturadas com 19 pais que se tornaram ativistas dos direitos das pessoas com defíciência, 15 mulheres e 4 homens, todos cidadãos portugueses entre os 30 e os 40 anos de idade, provenientes, principalmente, da classe trabalhadora e do setor terciário. Em termos metodológicos, o acesso ao trabalho de campo e aos primeiros interlocutores foi feito através da APPDA - Associação Portuguesa para as Perturbações do Desenvolvimento e Autismo, graças aos mesmos pais que sugeriram outros potenciais interlocutores e também através de uma etnografia online (Kozinets, 2010) de grupos de apoio e defesa dos direitos da pessoa com autismo, sendo que a maioria destas comunidades virtuais existe dentro de plataformas de mídias sociais como o Facebook (Clifford; Minnes, 2013). Além de conduzir entrevistas não estruturadas, conversas informais e interações virtuais (Bowler, 2010; Hine, 2015), a autora participou, junto com pais ativistas, em eventos públicos relacionados ao autismo e à deficiência (conferências, celebrações, reuniões, marchas), ou os encontrou em suas próprias casas. Todos os interlocutores contribuiram de forma voluntária ao estudo e deram consentimento explícito para o uso das entrevistas ao fim da pesquisa. Seus nomes são pseudônimos para garantir o anonimato. 
autismo deu origem a uma transformação e reorganização das relaçóes familiares e pessoais. Lembrar o momento da notícia do diagnóstico de autismo suscita nas mães reações emotivas muitos intensas e é geralmente interpretado, a posteriori, como um "novo início", a "entrada dentro de um universo desconhecido" ou o "ponto de viragem" da própria vida, uma análise confirmada por outros estudos sobre o mesmo tema (Grinker, 2007; Lickenbrock; Ekas; Whitman, 2011; Silverman, 2012). Dentro da perspetiva teórica sugerida pela Mol (1999, 2002), diríamos que a experiência do diagnostico de autismo desencadeia uma nova ontologia da maternidade, marcada pela dimensão temporal que é evocada nos discursos produzidos.

Esta seção apresenta três estudos de caso de mães de crianças diagnosticadas com autismo e tem como objetivo analisar como a revelação desse diagnóstico levou as mães a repensar a própria experiência da gravidez, os comportamentos e hábitos adotados durante a gestação, assim como a refletir criticamente acerca do papel da Medicina Diagnóstica pré-natal e, em particular, da validade do conjunto de tecnologias utilizadas durante a gravidez e que marcam o processo de gestáo e monitorização da gestação. De um lado, o diagnóstico de autismo produz uma transformação íntima da auto-representação das mulheres enquanto mães: o filosofo Ian Hacking, neste sentido, afirmaria que o autismo, como rótulo diagnóstico, é "interativo", chamando a atenção para o papel pragmático que as classificaçóes psiquiatricas têm (2006a, 2006b). Do outro lado, esta experiência dá também origem à uma reformulação, ou melhor, uma nova articulação do discurso ontológico das mães sobre a Medicina e as suas técnicas. De seguida, iremos explorar, em particular, como as narrativas das mães cujos filhos já receberam um diagnóstico de autismo póem em questão a presunção de neutralidade e transparência da leitura "técnica" do corpo grávido. Especificamente, a inexistência até hoje de um exame pré-natal capaz de detectar o autismo é interpretada pelas mães como um atraso e uma falha da Medicina Diagnóstica e preventiva contemporânea, que impossibilita o direito das mulheres de poder "escolher" interromper, ou não, a gravidez, assim como a possibilidade de preparar o acolhimento de uma criança com necessidades especiais. As mães, porém, utilizam estrategicamente 
o atual insucesso das técnicas de diagnóstico pré-natal de "ver" o autismo dentro do útero como uma maneira de resistir à implantação de políticas eugênicas em relação ao autismo.

\section{Joana: será que eu fiz alguma coisa mal?}

No principio quando soube que o meu filho era autista senti uma grande culpa... aconteceu alguma coisa na gravidez? será que eu fiz alguma coisa mal? o que é que eu fiz? ainda por cima como não há uma causa determinada [do autismo] eu estava mesmo ansiosa, quer dizer ninguém me consegue explicar se algo correu mal na gravidez? ninguém diz que sim, mas também ninguém diz que não, certezas não há e eu tenho de arranjar maneira de trabalhar esta sensação [...] porque quer dizer, eu tive todos os cuidados nesta gravidez, todos! Senti-me impotente, revoltada e muito confusa...quando consultamos o médico que afinal disse que o meu filho tinh a comportamentos autistas foi como se me tivessem aberto um alçapão, puxaram-me o tapete! senti uma revolta muito grande, uma sensação de impotência perante uma condição que eu sabia que seria para toda a vida, senti-me revoltada pois eu fui muito consciente durante esta gravidez, tomei as vitaminas, fiz os exames que tinha que fazer, isso revoltou-me completamente, não dormia a noite a pensar nas possiveis causas que deram origem ao seu autismo, talvez podia ter feito algo mais, os médicos talvez não tiveram o cuidado necessário, sei lá eu se gastando $500 €$ podiamos saber se eu ou o seu pai tínhamos alguns genes disto! mas nunca me foi dito nada. Imagina que há uma estrutura privada no estrangeiro que faz testes, achas que nós sabemos tudo? há coisas experimentais que só daqui a 20 anos é que entram no mercado mas entretanto há pessoas que agora estão a fazer parte destas experiências pioneiras, eu não digo que mudava as coisas, quer dizer eu nunca voltaria atrás, nunca mudava o meu Pedro... mas ninguém sabia nada disso, portanto [o diagnóstico] foi uma coisa inesperada, percebes? É a mesma ideia de medicina que deveria mudar!

A Joana é uma jovem fotógrafa de 36 anos, que trabalha a meio período numa loja de estética. O movimento inquieto dos seus olhos trai o som calmo e pousado das suas palavras. $\mathrm{O}$ que ressalta na sua narrativa é a dúvida - misturada com uma sensação de culpa, remorso, mas também de revolta - se algo poderia ter sido feito para que ela 
pudesse de qualquer forma preparar-se a acolher um filho com autismo. Depois de muitas suspeitas acerca do comportamento "bizarro" do Pedro e após ser sido direcionada por uma médica pediatra para uma consulta com um pedopsiquiatra é que a Joana "descobre" o autismo do seu filho, na altura, com 3 anos e meio. De acordo com sua etimologia,

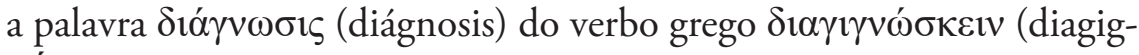
nốskein) - que significa "discernir", "distinguir" - o diagnóstico é uma prática biomédica graças à qual um profissional de saúde, através de um conjunto de técnicas e instrumentos biomédicos, distingue os traços e sintomas específicos de uma condiçâo médica e identifica suas causas, possíveis evoluçôes e estratégias terapêuticas. Como as palavras da Joana mostram, porém, o diagnóstico configura-se também como uma experiência emocional exigente e desafiadora.

$\mathrm{Na}$ altura da sua gravidez, Joana foi aconselhada a tomar medidas proativas para prevenir problemas que podem complicar a gestaçáo e o normal desenvolvimento do feto. É sobre este assunto que Joana ainda hoje se questiona: será que ela podia ter tido mais cuidado do que ela de fato teve durante os nove meses de gravidez? A este respeito, Joana recorda que tinha lido como as crianças nascidas de máes com deficiência de ferro, um elemento fundamental para o desenvolvimento do cérebro no feto, têm cinco vezes mais possibilidade de desenvolver autismo, e que este risco poderia aumentar se a mãe tivesse mais que 35 anos ou uma condição metabólica como obesidade, hipertensão ou diabetes. Durante a sua gravidez, portanto, ela decidiu tomar os suplementos de ferro e afirma que, se não os tivesse tomado, talvez o grau de autismo do seu filho poderia ser mais grave. Também afirma ter controlado o peso na gravidez, tentando de não ganhar mais do que 15 quilos, para prevenir problemas como diabetes e pressão alta, pois se lembra de o seu ginecologista ter-lhe falado da possibilidade que o excesso de gordura corporal poderia ter em alterar os níveis hormonais da mulher e afetar, assim, o desenvolvimento do cérebro no feto. Ao longo da sua entrevista, porém, Joana também questiona o conhecimento médico sobre o autismo: será que os médicos - se melhor informados - poder-lhe-iam ter sugerido a existência de testes genéticos experimentais? 
O relato de Joana mostra como o diagnóstico de autismo foi “inesperado", trazendo para ela sentimentos de desespero, mas também de raiva e revolta. A este respeito, alguns estudos destacam como, mesmo muito tempo depois de ter sabido do diagnóstico da criança, as mães revelam estar ainda a viver uma luta emocional interior, devido à passada experiência do diagnóstico, assim como a um processo contínuo de reorganização do próprio cotidiano e de expectativas futuras (Abbott; Bernard; Forge, 2013; Wachtel; Carter, 2008). Para a Joana, a experiência do diagnóstico foi um ponto de partida de um "re-pensamento" crítico não só dos seus hábitos, expectativas de maternidade e desejos futuros, mas também do saber da Biomedicina sobre o autismo, assim como da validade das atuais biotecnologias de diagnóstico pré-natal. Neste sentido, o estudo de Cussins sobre as interaçóes entre mulheres e tecnologia médica, baseado no seu trabalho de campo nas clínicas de infertilidade, foi pioneiro em questionar o argumento segundo o qual as tecnologias reprodutivas favorecem a objetificação das mulheres e uma alienação de si mesmas (Cussins, 1996, p. 576-77). A autora desenvolve, então, a noção de 'coreografia ontológica' para sublinhar a existência de interaçóes contínuas entre as mulheres "sujeitas" às tecnologias médicas e estas últimas: são estas interaçóes que constroem uma coreografia, isso é um conjunto de discursos ontológicos sobre um determinado fenômeno.

Apesar de Joana saber da inexistência ,até o dia de hoje, de exames ou testes clínicos pré-natais comprovados e capazes de diagnosticar alteraçôes neuronais ou genéticas ligadas a um possível risco de desenvolvimento do autismo, no seu discurso emerge a consciência crítica de que, mais do que os médicos em si, é a mesma ideia de Medicina (diagnóstica) que tinha que ser posta em causa: o seu corpo grávido torna-se a posteriori o lugar onde a Medicina não conseguiu aplicar com sucesso o seu poder de ver. Este último aspecto é evidente na narrativa da Bárbara, uma mulher de 42 anos, ativista dos direitos das pessoas com deficiência e mãe de Gonçalo, um rapaz com TEA com 14 anos.

\section{Bárbara: a Medicina, afinal, não é tão infalível}

Eu acho que os médicos estão muito focados nos nossos filhos e ao mesmo tempo eles acham que nós mães deveríamos ter feito mais, olha, não 
tenho papas na língua! Essas ideias para pessoas como nós, que estamos tão fragilizadas naquele momento do diagnóstico, levam logo para a culpabilização, estás a compreender? Eles têm que saber que não é por aí que eles podem ajudar, durante a gravidez disseram o que é que eu devia fazer e esse apoio é fundamental, às vezes estão a fazer um bom trabalho, mas não sei, nunca ninguém se preocupou de dizer que a medicina afinal não é tão infalivel, estás a perceber? A tela [do ultrassom] não é uma bola de cristal, eles conseguem ver ou não ver, não têm culpa, mas poderiam na mesma ser mais preparados e falar com as mães que o que sabem é limitado [...] não é nada pessoal, mas eu acho que ainda os técnicos às vezes não admitem que não sabem, a maior dificuldade que eu tenho é esta, onde é que acaba o saber deles e onde é que começa o poder, ai é que está a questão, não sei se estás a perceber, ai é que está a minha maior dificuldade, a do meu marido e de toda a gente em casa, porque assim a gente fica com dúvidas, isso será da medicina que ainda não chegou tão a frente? Será que eles não aceitam isso?

Entre as tecnologias de diagnóstico pré-natal, as técnicas de imagiologia, como a ecografia obstétrica, desempenham um papel crucial na Medicina contemporânea, assim como no senso comum. Não é um acaso que, de acordo com Van Dijck (2005), as mulheres grávidas coloquem tanta confiança nas evidências visuais da gestação, do estado de saúde do feto e no eventual diagnóstico médico. A Bárbara levanta uma questão central em torno do debate sobre estas técnicas de diagnóstico, isto é, a ambiguidade da ideia de transparência e infalibilidade que lhes é atribuída, seja nos usos ou nos significados que elas contribuem a produzir.

O estudo de Van Dijck é significativo no que diz respeito à sua análise do desenvolvimento das tecnologias de imaging, a partir do fim do século XIX e início do século XX, das imagens do corpo interior e dos saberes sobre este corpo que são construídos a partir delas. A ultrassonografia é, neste sentido, uma técnica de leitura do útero da mulher, onde o saber do técnico de saúde - capaz de ler, interpretar e codificar as imagens - articula-se com o poder que é atribuído à mesma técnica (e as imagens que ela produz): isto é, o poder de ler o corpo da mulher de uma forma transparente e neutra. Como o autor sublinha, a presunção de neutralidade e transparência da leitura "técnica" do corpo grávido "implica a 
ideia de que a tecnologia de ultrassom fornece principalmente informaçôes médicas objetivas sobre o estado de saúde do feto"10 (Van Dijck, 2005, p. 114, traduçáo nossa). A forma como os médicos visualizam as possíveis patologias pré-natais promove uma concepção específica delas $\mathrm{e}$, de consequência, afeta também a forma como a sociedade discerne e aborda essas mesmas patologias (ibid., p. 12). De acordo com estas reflexôes, o caso do autismo é paradigmático, pois, o fato de não ser detectável através da ultrassonografia - o autismo não é algo detectável fisicamente - contribui para, e até reforça, a nosso ver, a idéia (e a metáfora) da sua natureza oculta, incognoscível.

\section{Zélia: para mim era mesmo uma luta para a diversidade}

Uma mãe tem que remar contra o sistema, contra o que está instituído, os médicos têm que moderar um bocado aquela autoridade porque a forma como lidam com as mães eu acho que é muito importante, a maneira de falar é essencial [...] uma mãe é tratada como uma boneca, faça isso! Faça aquilo! Não gosto que me mintam, nem que me ponham paninhos quentes, gosto que sejam diretos a falar [...] às vezes sinto um sentimento de culpa quando me parece que o Tiago está triste, será que eu fiz bem em dar-lhe vida? As mães nunca se habituam a esta situaçâo e às vezes é constrangedor, magoa-nos cá dentro [toca-se no esterno] mas ele é o meu filho e embora tínhamos idealizado um filho sem problemas deste tipo... pronto, esta situação caiu-nos em cima, de repente. Às vezes pergunto-me se com a ajuda dos médicos tudo isso podia ter sido diferente, dizemos assim. Se eu tivesse sabido que o meu filho podia ter um risco $\mathrm{x}$ de ter autismo, náo sei, até podia ter pensado de ir para a frente na mesma, percebes? Mas com outra consciência, mais preparada talvez a tudo isso, porque muitas vezes parece que a culpa é nossa. No caso da trissomia 21 [Síndrome de Down], quer dizer os pais [que decidem abortar] não têm culpa, não é? As mães que abortam não são monstros! Mas eu nunca teria feito, aliás acho que mesmo havendo possibilidade, não faria, porque o autismo tem a ver com a diversidade das pessoas e com a aceitação, e a nossa sociedade tem que aprender a li-

10 Tradução do original "it implies that ultrasound technology principally yields objective medical information on the health status of the fetus" 
dar com a diferença... para mim era mesmo uma luta para a diversidade, apesar de isso trazer muita dor, de ser uma escolha difícil! Nós mulheres não somos bonecas, percebes? Por isso, se um dia a medicina descobrir como fazer [como detectar o autismo na gravidez], que seja eu a decidir! [...] Tenho orgulho da mãe que sou e orgulho-me do meu filho, mas às vezes penso nisso, pelo menos na possibilidade que eu podia ter tido de escolher... talvez isso fazia com que eu fosse mais preparada, ficava mais informada"

Para a Zélia, o processo de aprendizagem e de adaptação às necessidades, traços e características comportamentais do seu filho Tiago - um rapaz de nove anos que apresenta um grau de autismo dito de nível 3 (severo), com dificuldade na comunicação verbal, déficit cognitivos e com uma tendência para o isolamento - foi difícil e doloroso, agravado pelo estigma social que muitas vezes ela viveu no espaço público. $\mathrm{O}$ ideal da boa mãe - tão persistentemente entrelaçado com a história do autismo enquanto categoria médica (Silverman, 2012), e as expectativas sociais que este mesmo ideal envolve, contribuíram para produzir e reforçar a noção de amor materno incondicional, um tópico largamente presente nas narrativas das mães sobre os próprios filhos com autismo (Lo Bosco, 2018). É a esse amor incondicional que Zélia se refere quando ressalta que ela nunca teria pensado no aborto, apesar das dificuldades que enfrenta no seu dia a dia em cuidar do seu filho. Assim como muitas outras mulheres entrevistadas, ela aborda de fato a possibilidade de que a amniocentese possa no futuro tornar-se útil para prognosticar o risco do desenvolvimento do autismo no feto, destacando, ao mesmo tempo, as complexas implicaçóes éticas de um possível rastreamento pré-natal e previsível interrupção da gravidez decorrente de veredictos positivos. De acordo com ela, a possibilidade para os pais de interromper a gravidez em caso de teste preditivo positivo - uma escolha possível por exemplo no caso da trissomia 21 (Síndrome de Down) - representa uma questão delicada e "até perigosa", pois ela questiona: "o que seria da nossa humanidade se não houvesse mais crianças com espectro autista? Os eliminamos mesmo? Temos certeza que queremos isso?". No entanto, ela acredita que o desenvolvimento de testes genéticos ou a individuação de biomarcadores do autismo, detectáveis através da análise do líquido amniótico, pode- 
riam dar às mães a possibilidade de "saber" sobre a condição da própria criança já durante a gestação: esta possibilidade é entendida como uma oportunidade para as mães de se preparar com antecedência para cuidar do próprio filho, mas também de reverter a relação de poder com os técnicos de saúde, "nós mulheres não somos bonecas".

Em linha com a sua luta como ativista para a defesa dos direitos das pessoas com autismo e deficiência intelectual, Zélia reinterpreta a ausência de técnicas diagnósticas até hoje aptas a detectar o autismo como uma estratégia para resistir a práticas eugênicas. Como mencionamos no início desta seção, depois de ter recebido o diagnóstico do próprio filho, as mães reconfiguram os próprios hábitos, reconstroem suas experiências de gravidez e descrevem o pós-diagnóstico como uma verdadeira "transformação", apresentando-se muitas vezes como pessoas diferentes desde então. No caso da Zélia, a auto-representação de si como mãe ativista, que defende a necessidade de aceitar e incorporar a diversidade humana, simboliza um dos aspectos do processo de reorganização da própria narrativa de vida e até uma forma - como ela mesma diz - de dar um sentido ao diagnóstico de autismo do Tiago. A comparação com a Síndrome de Down é, neste sentido, esclarecedora. Apesar de ela nunca exprimir juízos morais sobre as mães que decidem interromper a gestação após um resultado positivo para trissomia 21, é evidente como o aborto é reinterpretado por ela como uma possibilidade de aniquilar a diversidade humana. Zélia admite temer que os avanços na genética do autismo, por exemplo, possam levar à identificação de marcadores genéticos e, assim, ao emprego de testes genéticos pré-natais, persuadindo os pais a optar pelo aborto. Essa eventualidade pode ameaçar a presença da diversidade do autismo e, silenciosamente, um dia levar a uma homogeneização genética da humanidade. No ato de repensar o seu corpo grávido - objeto do discurso médico e das práticas de manipulação e visualização médica - Zélia articula, portanto, uma nova ontologia. Se, como vimos anteriormente, as tecnologias de diagnóstico pré-natal (desde a imagiologia até os testes genéticos e os rastreios) são as ferramentas ontológicas com as quais a Obstetrícia contemporânea funda a sua narrativa de transformação de arte à ciência, a ausência de técnicas de diagnóstico pré-natal para o autismo é, a 
posteriori, interpretada como uma falha, um atraso da Medicina Diagnóstica preventiva contemporânea, como a demonstração do seu saber limitado, incompleto. Por não poder ser detectado, o autismo derruba e confronta a suposta infalibilidade das técnicas diagnósticas e do olhar do técnico de saúde de "ver".

\section{Conclusões}

A constituição histórica do saber da Medicina como ciência infalível e objetiva é confrontada com os desafios contemporâneos inerentes à sua prática. No nosso caso específico, a relação entre "ver/saber" versus "não ver/não saber" é caracterizada para uma tensão que se desenvolve e acontece no corpo grávido da mulher, um dos lugares por excelência onde o não visto - o útero, o feto - torna-se visível e cognoscível, "nu" perante o olhar da Medicina e dos seus técnicos. A Medicina Diagnóstica baseia-se, neste sentido, na ideia de que o corpo grávido da mulher é como uma entidade transparente pronta para ser lida, inerte ao olhar do técnico (Van Dijck, 2005). A inexistência de avanços científicos sobre o diagnóstico pré-natal do autismo denunciam um não saber? A ineficácia das técnicas de diagnóstico atuais seria um dos aspectos que apontam uma falibilidade da ciência médica? Propomo-nos olhar para a articulação dinâmica das narrativas que os vários sujeitos sociais produzem para dar significado a coreografias ontológicas nas quais estão mobilizados.

Como mencionado na introdução, neste artigo nos propusemos analisar os dados etnográficos a partir da noção de "coreografia ontológica” de Cussins (1996), pois nos permite abordar as multíplices realidades sobre um determinado fenômeno, não focando nas perspectivas discordantes, mas na complexidade das suas co-existência, dependendo das temporalidades, dos contextos sociais e dos lugares, dos sujeitos envolvidos, e das tecnologias usadas. De acordo com esta perspectiva, se a primeira parte deste capítulo mostra como os médicos entrevistados elaboram a história da Obstetrícia portuguesa contemporânea, formulando uma ontologia da modernidade que articula as tecnologias de diagnóstico pré-natal com a transição política pós 25 de Abril, a segunda seção mostra como novos sujeitos, as mães de crianças diag- 
nosticadas com autismo, articulam uma própria (nova) ontologia sobre a Medicina Diagnóstica preventiva e as suas técnicas (ultrassonografia, amniocentese, testes genéticos) a partir das proprias experiências sobre a alegada transparência e plasticidade do corpo grávido. As diferentes narrativas ontológicas produzidas pelo varios sujeitos considerados (médicos e mães) acerca do papel das técnicas de diagnóstico mostram, portanto, a dimensão temporal e, assim, a dinâmica da constituição de uma "coreografia ontológica” sobre a Medicina Diagnóstica pré-natal e a presunção de neutralidade e transparência da leitura "técnica" da maternidade.

\section{Referências}

ABBOTT, M.; BERNARD, P.; FORGE, J. Communicating a diagnosis of Autism Spectrum Disorder - a qualitative study of parents' experiences. Clinical Child Psychology and Psychiatry, v. 18, n. 3, p. 370-382, 2013.

ALMEIDA, A. N. de. Os mundos da infância: olhares, espaços e personagens. In: ALMEIDA, A. N. (org.), História da Vida Privada em Portugal: Os Nossos Dias. Lisboa: Circulo de Leitores/ Temas e Debates, 2011. p. 142-173.

AMERICAN PSYCHIATRIC ASSOCIATION (APA), Autism Spectrum Disorder, 2015. Disponível em <https://www.psychiatry.org/patients-families/autism/what-is-autism-spectrum-disorder>.

AUYEUNG, B.; et al. Fetal testosterone and autistic traits. British Journal of Psychology, v. 100, n. 1, p. 1-22, 2009.

BARRETO, M. R. N. A Ciência do Parto nos Manuais Portugueses de Obstetricia. Niterói, v. 7, n. 2, p. 219-236, 2007.

BOWLER, G. Netnography: A Method Specifically Designed to Study Cultures and Communities Online. The Qualitative Report, v. 15, n. 5, p. 1270 75, 2010.

CLEMINSON, R.. Catholicism, Race and Empire: Eugenics in Portugal, 1900-1950. Budapest: Central European University Press, 2014.

CLIFFORD, T.; MINNES, P. Logging On: Evaluating an Online Support Group for Parents of Children with Autism Spectrum Disorders. Journal of Autism and Developmental Disorders, v. 43, n. 7, p. 1662-75, 2013. 
CUSSINS, C.. Ontological Choreography: Agency through Objectification in Infertility Clinics. Social Studies of Science, v. 26, n. 3, p. 575-610, 1996.

DE LUCA, F. "God was the first anaesthetist": obstetrics and pain in Lisbon at the turn of the 20thcentury. Etnográfica, v. 22, n. 3, p. 619-642, 2018.

FEDELE, A.; WHITE, J. (org.). Birthing matters in Portugal: Anthropological Explorations. Etnográfica, ano 22, n.3, 2018.

FERREIRA, V. S. Modas e modos: a privatização do corpo no espaço público português. In: ALMEIDA, A. N. (org.), História da Vida Privada em Portugal: Os Nossos Dias. Lisboa: Circulo de Leitores/ Temas e Debates, 2011. p. 242277.

GOMES, P.; et al. Autismo no Brasil, desafios familiares e estratégias de superação: revisão sistemática. Jornal de Pediatria, v. 91, n. 2, p. 111-121, 2015.

GRINKER, R. Unstrange Minds: Remapping the World of Autism. New York: Basis Books, 2007.

HACKING, I. Making Up People: clinical classifications. London Review of Books, v. 28, n. 16, p. 23-26, 2006 a.

HACKING, I. O autismo, o nome, o conhecimento, as instituiçóes, os autistas - e suas interaçóes. In: RUSSO, M., CAPONI, S. (Orgs.). Estudos de filosofia e história das ciências biomédicas. São Paulo: Discurso Editorial, 2006b.

HINE, C. Ethnography for the Internet: Embedded, Embodied and Everyday. London: Bloomsbury Academic, 2015.

KOZINETS, R. Netnography: Doing Ethnographic Research Online. London: SAGE Publications, 2010.

LICKENBROCK, D. M.; EKAS, N. V.; WHITMAN, T. L. Feeling good, feeling bad: influences of maternal perceptions of the child and marital adjustment on well-being in mothers of children with an autism spectrum disorder. Journal of autism and developmental disorders, v. 41, n. 7, p. 848-858, 2011.

LO BOSCO, M. A call for a broader citizenship: parent-led autism advocacy movement in Portugal. 2018. Tese (Doutorado em Antropologia da Saúde) Universidade de Lisboa, Instituto de Ciências Sociais, Lisboa, 2018. 
MARTIN, E. The Woman In The Body: A Cultural Analysis Of Reproduction. Boston: Beacon Press, 2001 [1987].

MOL, A. Ontological politics: A word and some questions. In: LAW, J.; HASSARD, J. (Eds.). Actor Network Theory and After. Oxford: Blackwell, 1999. p. 74-89.

MOL, A. The body multiple: ontology in medical practice. Durham, North Carolina: Duke University Press, 2002.

MORGAN, L. M. Mediated Bodies. Fetal Bodies, Undone. In MASCIA-LEES, F. E. (org.). A companion to the anthropology of the body and embodiment. Chichester, West Sussex: Blackwell Publishing, 2011. p. 320-337.

NEVES, J. P.; AYRES-DE-CAMPOS, D. Mortalidade materna em Portugal desde 1929. Acta Obstétrica e Ginecológica Portuguesa, v. 6, n. 3, p. 94-100, 2012.

OLIVEIRA, G.; et al. Epidemiology of Autism Spectrum Disorder in Portugal: Prevalence, Clinical Characterization, and Medical Conditions. Developmental Medicine and Child Neurology, v. 49, n. 10, p. 726-33, 2007.

RAPP, R. Testing Women, Testing the Fetus: The Social Impact of Amniocentesis in America. New York and London: Routledge, 2000.

ROBINSON E.; et al. Genetic research in autism spectrum disorders. Current Opinion in Pediatrics, v. 27, n. 6, p. 685-691, 2015.

SACADURA, S. C. C. Alguns aspectos clínicos e sociaes da Obstetrícia: Puericultura, Consultas Pré-natais, Higiene da Gestação, Protecção das Futuras Mães, Separata de Acção Médica, v. 8, 1938.

SACADURA, S. C. C. Dois Problemas de Assistência: o trabalho da mulher fora do lar; parto no domicílio ou nas maternidades. Lisboa: Imprensa Médica, 1939.

SEIZE, M.; BORSA, J. Instrumentos para Rastreamento de Sinais Precoces do Autismo: Revisão Sistemática. Psico-USF, v. 22, n. 1, p. 161-176, 2017.

SILVERMAN, C. Understanding Autism: Parents, Doctors, and the History of a Disorder. Princeton, NJ: Princeton University Press, 2012. 
STONER, R.; et al. Patches of Disorganization in the Neocortex of Children with Autism. New England Journal of Medicine, v. 370, n. 13, p. 1209-1219, 2014.

TAYLOR, J. S. The public life of the fetal sonogram: technology, consumption, and the politics of reproduction. New Brunswick, New Jersey, and London: Rutgers University Press, 2008.

THOMPSON, C. Making parents : the ontological choreography of reproductive technologies. Cambridge, Massachusetts London, England: The MIT Press, 2005.

VAN DIJCK, J. The Transparent Body: A Cultural Analysis of Medical Imaging. Seattle, London: University of Washington Press, 2005.

VICENTE, A. Mulheres em Discurso. Lisboa: Imprensa Nacional - Casa da Moeda, 1987.

WACHTEL, K.; CARTER, A. S. Reaction to diagnosis and parenting styles among mothers of young children with ASDs. Autism, v. 12, n. 5, p. 575594, 2008.

WENDLAND, C. L. The Vanishing Mother: Cesarean Section and "Evidence-Based Obstetrics”. Medical Anthropology Quarterly, v. 21, n. 2, p. 218-233, 2007.

WHITE, J. 'But Isn't It the Baby that Decides When It Will Be Born ?': Temporality and Women's Embodied Experiences of Giving Birth. The Cambridge Journal of Anthropology, v. 34, n. 1, p. 72-86, 2016. 


\section{SOBRE AS AUTORAS E AUTOR:}

\section{Alejandra Roca}

Doutora em Antropologia pela Universidad de Buenos Aires (UBA), onde dirige projetos interdisciplinares em Ciência e Tecnologia, Políticas Públicas e tecnologias vinculadas à saúde e o corpo. Professora de Graduação e Pós-graduação da UBA e da Universidad Nacional de José Paz (UNPAZ). Tem atuado em organismos nacionais de gestão em Ciência e Tecnologia e impulsionado a Red de Antropología de la Ciencia y la Tecnología Argentina e a Red Interuniversitaria de Popularización de la Ciencia y la Tecnología.

\section{Brunno Souza Toledo Pereira}

Graduando em Ciências Sociais na Unicamp (Bacharelado e Licenciatura). Integrante do Labirinto, desenvolve pesquisa de iniciação científica sobre o tema "Divulgação científica e terapia celular: um enfoque sobre as narrativas sobre células mesenquimais e sangue menstrual" (PIBIC-SAE/Unicamp 2019-2020).

\section{Camila Silveira Cavalheiro}

Graduanda em Ciências Sociais na Universidade Federal do Rio Grande do Sul (UFRGS) - Bacharelado. Técnica em Química pelo Instituto Federal de Educação, Ciência e Tecnologia do Rio Grande do Sul (IFRS) - Campus Caxias do Sul. Bolsista de Iniciação Científica (PROBIC/UFRGS 2020-2021), integra o grupo de pesquisa "Ciências na vida: Produção de conhecimento e articulaçóes heterogêneas".

\section{Cecilia Rustoyburu}

Investigadora Adjunta do Consejo Nacional de Investigaciones Científicas y Técnicas (CONICET/Argentina). Trabalha no Centro de Estudios Sociales y Políticos da Universidad Nacional de Mar del Plata (UNMDP). É Professora Adjunta da cátedra Sociología de la Ciencia y la Tecnología, no Departamento de Sociología da Facultad de Humanidades. É Professora e Licenciada em Historia (UNMDP) e Doutora em 
Ciências Sociais (Universidad de Buenos Aires). Realizou Pós-doutorado no Departament d'Antropologia Social i Història d'Amèrica i Àfrica da Universitat de Barcelona.

\section{Chiara Pussetti}

Doutora em Antropologia pela Universidade de Turim (Itália, 2003). Atualmente é Investigadora Auxiliar no ICS e Professora no Doutoramento em Antropologia da Universidade de Lisboa (DANT-UL). Desde 2017 é Investigadora Principal pelo ICS-ULisboa da equipe nacional do projeto "ROCK. Regeneration and Optimisation of Cultural heritage in creative and Knowledge cities", financiado pelo programa-quadro Horizonte 2020 ( www.rockproject.eu), e do projeto "EXCEL. The Pursuit of Excellence. Biotechnologies, enhancement and body capital in Portugal", financiado pela Fundação para a Ciência e a Tecnologia (PTDC/SOC-ANT/30572/2017).

\section{Daniela Tonelli Manica}

Pesquisadora do Laboratório de Estudos Avançados em Jornalismo (Labjor/Nudecri/Unicamp). Coordena o Labirinto, Laboratório de estudos socioantropológicos sobre Tecnologias da Vida, e é coprodutora do podcast Mundaréu, dedicado à divulgação científica de Antropologia.

\section{Débora Allebrandt}

Professora Adjunta da Universidade Federal de Alagoas. Bacharel em Ciências Sociais (2005), Mestre em Antropologia Social pela Universidade Federal do Rio Grande do Sul (2008), e doutora em Antropologia pela Université de Montréal (2013). Entre 2013-2015, realizou Pós-doutorado no PGAS/UFRGS. Desenvolve trabalhos sobre Parentesco e Ciência, e sua atuação se estende aos seguintes temas: Estudos Sociais da Ciência, Direitos Humanos, Políticas Públicas, Direitos Sexuais e Reprodutivos, Antropologia e Ética. 


\section{Fabíola Rohden}

Professora do Programa de Pós-Graduação em Antropologia Social e do Departamento de Antropologia da Universidade Federal do Rio Grande do Sul. Pesquisadora do CNPq e do Núcleo de Antropologia do Corpo e da Saúde (NUPACS/UFRGS). Coordenadora do Grupo de Pesquisa Ciências na Vida (CNPq/UFRGS). Realizou Mestrado e Doutorado em Antropologia Social na UFRJ (PPGAS/Museu Nacional) e Pós-doutorado na Universidade Livre de Amsterdã. Desenvolve investigaçôes nas áreas de Relaçôes de Gênero, Corporalidades e Subjetividades, Sexualidade, Gênero e Ciência, e Biomedicalização.

\section{Francesca De Luca}

Antropóloga, Doutoranda pelo Instituto de Ciências Sociais da Universidade de Lisboa. A sua tese de doutoramento desenvolve uma Genealogia da Maternidade em Portugal, a partir da análise de práticas e discursos obstétricos sobre a dor. É Investigadora no projeto EXCEL (ICS-UL) que estuda Biotecnologias de Aprimoramento Humano. É membro do Coletivo EBANO, com o qual desenvolve trabalhos transdisciplinares que cruzam Antropologia e práticas artísticas.

\section{Glaucia Maricato}

Pesquisadora Associada na Universidade Livre de Berlim, na qual desenvolve pesquisa de pós-doutoramento em torno de tecnologias, práticas e efeitos da produção de evidências epidemiológicas. Graduada em Ciências Sociais, Mestre e Doutora em Antropologia Social pela Universidade Federal do Rio Grande do Sul (UFRGS), nos últimos oito anos, desenvolveu projetos de pesquisa sobre enredamentos entre saberes científicos, demandas políticas e medidas de intervenção em torno da hanseníase.

\section{Isabel Pires}

Antropóloga, Mestre em Migraçôes, Interetnicidades e Transnacionalismo. Atualmente é Doutoranda em Antropologia no Instituto de Ciências Sociais da Universidade de Lisboa. Pertence ao projeto EX- 
CEL: A Busca da Excelência - Biotecnologias, Valorização e Capital Corporal em Portugal (PTDC / SOC-ANT / 30572/2017), ICS-ULisboa. Sua investigação atual centra-se nas repercussóes sociais, políticas e econômicas da emergência em Portugal de um mercado cosmético "étnico" transnacional, especialmente direcionado para a população migrante chinesa.

\section{Janaína Freitas}

Doutoranda em Antropologia Social (PPGAS/UFRGS), com estágio doutoral no Department of History of Science da Harvard University. Mestre em Antropologia Social e graduada em Ciências Sociais, é Pesquisadora Associada ao Núcleo de Pesquisa em Gênero e Sexualidade (UFRGS) e ao "Ciências na Vida: produção de conhecimento e articulações heterogêneas" (UFRGS). Seus interesses de pesquisa focam as temáticas de Gênero e Sexualidades, Ciência e Tecnologia, Corpo e Saúde, Teoria Queer.

\section{Jane Russo}

Professora Titular do Programa de Pós-Graduação em Saúde Coletiva do Instituto de Medicina Social (IMS) da UERJ. Possui Doutorado em Antropologia pela UFRJ/Museu Nacional e Pós-Doutorado pela EHESS (Paris). Vinculada ao Centro Latino-Americano em Sexualidade e Direitos Humanos (CLAM/IMS-UERJ), onde conduziu investigaçóes sobre a Sexualidade nas classificaçóes psiquiátricas, a institucionalização da Sexologia contemporânea e a consolidação da Medicina Sexual. Tendo como pano de fundo o papel dos hormônios na produção de novos modos de entender o corpo e a subjetividade, investiga a transformação contemporânea do conjunto de ideias e práticas que cercam a gestação, o parto e a maternidade.

\section{Jéssica Brandt da Silva}

Mestranda no Programa de Pós-Graduação em Antropologia Social da UFRGS. É Pesquisadora Associada ao grupo Ciências na Vida/ UFRGS e Bacharel em Ciências Sociais pela mesma Universidade. Suas 
pesquisas versam sobre as cirurgias plásticas, os usos de mídias sociais digitais e os processos de subjetivação que envolvem tais tecnologias.

\section{Maria Concetta Lo Bosco}

Gestora do projeto "The Color of Labour", financiado pelo European Research Council (AdG 695573), no Instituto de Ciências Sociais da Universidade de Lisboa. Integra o projeto "EXCEL. A busca da excelência” (PTDC / SOC-ANT / 30572/2017), onde explora o tema do aprimoramento cognitivo farmacológico e o uso de produtos biotecnológicos nas práticas de bio-hacking. Em seu doutorado, investigou as experiências dos pais com crianças diagnosticadas com Transtornos do Espectro do Autismo e o seu uso da rede social para promover os direitos das pessoas com deficiência intelectual.

\section{Marina Nucci}

Pesquisadora de pós-doutorado do Instituto de Medicina Social da Universidade do Estado do Rio de Janeiro (IMS/ UERJ), Bolsista Faperj Nota 10. Possui graduação em Ciências Sociais pela Universidade Federal do Rio de Janeiro (UFRJ), e mestrado e doutorado em Saúde Coletiva pelo IMS/ UERJ. Realiza pesquisas nas áreas de Gênero, Saúde e Estudos Sociais da Ciência.

\section{Marcelle Schimitt}

Doutoranda e mestra em Antropologia Social pela Universidade Federal do Rio Grande do Sul (UFRGS). Pesquisadora associada ao grupo Ciências na Vida: Produção de Conhecimento e Articulações Heterogêneas. Desenvolveu pesquisas sobre Gênero, Sexualidade, aprimoramentos corporais e os limites entre Estética e reparação no contexto das cirurgias plásticas realizadas a partir do Sistema Único de Saúde (SUS). Atualmente estuda os procedimentos cirúrgicos de reparação/ normalização das fissuras labiopalatinas e a centralidade estética e funcional da face nesse âmbito. 


\section{Tatiane Pereira Muniz}

Doutoranda no Programa de Pós-graduação em Antropologia Social da Universidade Federal do Rio Grande do Sul. Professora no Instituto Federal de Educação Ciência e Tecnologia da Bahia. Mestre em Antropologia pela Universidade Federal da Bahia, desenvolvendo projeto de pesquisa na área de Saúde e Etnicidade. Atualmente dedica-se a pesquisas nas áreas de Antropologia da Ciência, Estudos Sociais de Ciência e Tecnologia e Relaçôes Raciais no Brasil, investigando os processos de materialização da raça nas narrativas e práticas biomédicas. 
Esta coletânea apresenta 12 trabalhos inéditos que discutem o papel das biotecnologias nos processos de produção ou transformação corporal e subjetiva, por meio de investigações sediadas no Brasil, em Portugal e na Argentina. É resultado da articulação promovida pela Rede de Investigações Biotecnologias, Saúde Pública e Ciências na Vida que integra pesquisadoras e pesquisadores dedicadas/os a investigar a produção e repercussões do conhecimento e práticas biotecnológicas em diversos cenários. O eixo central das discussões gira em torno de como novas possibilidades tecnocientíficas direcionadas ao corpo e estruturadas nas chamadas Ciências da Vida traduzem uma série de tensões características das sociedades contemporâneas. Os capítulos constituem investimentos etnográficos e analíticos originais em cenários nos quais as tensões acerca de saúde e aprimoramento são reveladoras também do privilégio dado ao investimento individual em contraste com a ênfase na dimensão social ou coletiva, evidenciando, igualmente, os condicionantes econômicos e políticos em cena e a (re)produção de assimetrias sociais.

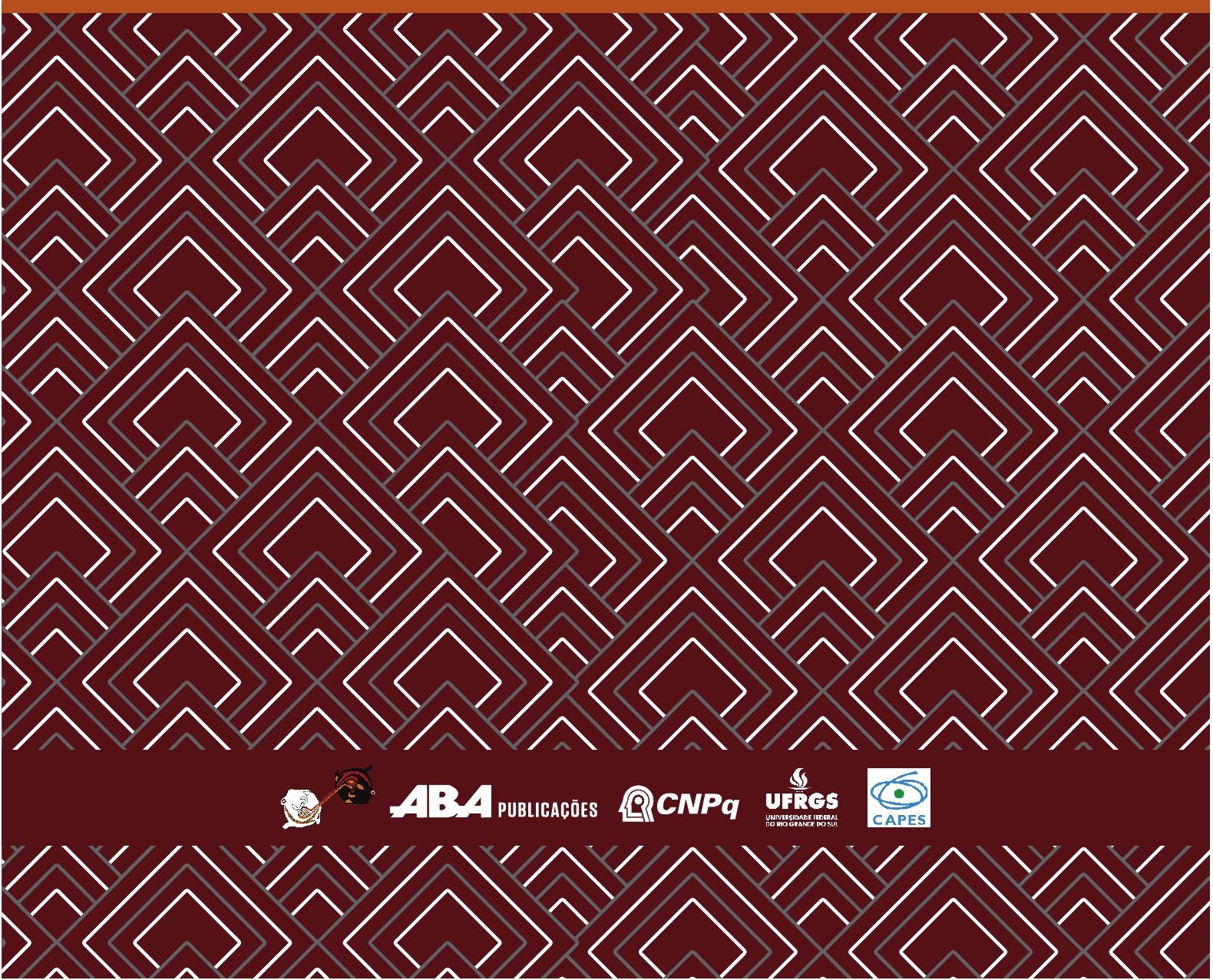

